\title{
A fuzzy data envelopment analysis based on credibility theory for estimating road safety
}

\author{
Mohaddeseh Amini ${ }^{a *}$, Rahim Dabbagha and Hashem Omrania
}

${ }^{a}$ Faculty of Industrial Engineering, Urmia University of Technology, Urmia, Iran

\begin{tabular}{l}
\hline C H R O N I C L E \\
\hline Article history: \\
Received December 2, 2018 \\
Received in revised format: \\
December 20, 2018 \\
Accepted January 4, 2019 \\
Available online \\
January 5, 2019 \\
\hline Keywords: \\
Road safety \\
Data envelopment analysis based \\
road safety \\
Fuzzy sets \\
Credibility theory
\end{tabular}

\begin{abstract}
A B S T R A C T
Road accidents as a global challenge, imposing irreparable financial and human life losses in almost all countries, especially in developing countries, annually. According to world health organization (WHO), if this trend continues, road accidents will become the 7th cause of human death by 2030. Thus, road safety policy makers have been trying to use safety promotion and preventative actions. In this paper, the road safety performance of Iranian provinces is studied. To evaluate road safety efficiency scores, data envelopment analysis based on road safety (DEARS) method in two deterministic and non-deterministic situations is used. To consider the uncertainty in input and output data, this paper develops credibility DEA-RS (CreDEA-RS) model. In fact, the constraints of DEA-RS model are considered as credibility constraints and a counterpart credibility DEA-RS (CreDEA-RS) model is proposed for evaluating road safety of provinces of Iran. According to the results, provinces located in mountainous and forest areas such as Gilan had a much weaker performance than provinces in desert areas such as Yazd.
\end{abstract}

C) 2018 by the authors; licensee Growing Science, Canada.

\section{Introduction}

Transportation sector is very important sectors in every country. Performance assessment of transportation systems has been an important and common issue among researchers and policy makers. One of the most important sectors in transportation is road transportation. There are new challenges in this sector such as road traffic, accidents and safety. Road accidents became as a global problem to societies due to imposing irreparable financial and human life losses. In fact, the issue of road traffic fatalities and injuries has known as public health and socioeconomic challenge in almost all societies (Bao et al., 2011). According to the world health organization (WHO, 2015) report, about 1.25 million people around the world die and in addition to this deaths, between 20 and 50 million people incur nonfatal injuries each year because of road traffic accidents. Road safety researchers believed that road accident are not consequences of only human errors (Shen et al., 2015). Therefore, they use term "crash" instead of "accident". By this consideration, a major part of these crashes are both preventable and predictable. Hence, policy makers try to incorporate intervention programs in road safety policies. In addition, implementation of road safety programs needs to monitor and evaluate the effectiveness of designed policies. In recent years, several models have been applied by researchers for evaluating road safety. Hermans et al. (2009) applied data envelopment analysis (DEA) for evaluating road safety

\footnotetext{
* Corresponding author. Tel: +98-4433554180, Fax: +98-4413554181

E-mail address: Amini.mo999@gmail.com (M. Amini)

(C) 2019 by the authors; licensee Growing Science, Canada. doi: $10.5267 /$ j.dsl.2019.1.001
} 
performance in 21 European countries with six criteria of visibility, speed, protective systems, infrastructure, vehicle and trauma care as evaluation indexes. Gitelman et al. (2010) developed a composite road safety indicator for benchmarking 27 European countries. In order to combine single indicators and construct a composite indicator, they used principal component analysis (PCA) and common factor analysis weighing models. Wegman and Oppe (2010) proposed a framework for the development of a comprehensive set of indicators to benchmark road safety performances of 23 European countries. Shen et al. (2012) combined hierarchy structured safety performance indicators (SPI) with DEA model to benchmark 28 European countries. Yannis et al. (2012) presented a theoretical concept for determining a SPI as a benchmark for cross-region comparisons. They applied proposed a method in some pilot countries. Bao et al. (2012) applied SPI which is related to crashes and injuries data in a hierarchy fuzzy TOPSIS model to evaluate the road safety in a set of European countries. They claimed that the SPI can evaluate road safety concepts better than single indicators. Aron et al. (2013) mentioned that most countries face with their specific road safety problems. In fact, socioeconomic, population, motorization level and road safety experiences are vary from region to region. Shen et al. (2015) proposed a DEA-based road safety model to evaluate road safety performance of 10 European countries. In order to rank European countries, they applied weight restriction method in DEA model. In final ranking, United Kingdom maintained the best performance among 10 countries. Chen et al. (2016) in order to benchmarking European countries used entropy embedded rank-sum ratio with SPI. Wang and Huang (2016) developed a Bayesian hierarchical joint model to evaluate road network safety to help the policy makers of road safety.

Rosic et al. (2017) used and integrated DEA-TOPSIS-PROMETHEE-RS model for evaluating road safety in Serbia. They calculated the efficiencies based on DEA and TOPSIS models and then, applied PROMETHEE to select the optimal method for constructing $\mathrm{n}$ composite index. Nikolaou and Dimitriou (2018) investigated road safety within the countries of European Union (EU). They also proposed targets for EU countries based on DEA and cross-efficiency DEA models. Behnood (2018) defined five pillars of road safety development for comparing Iran amongst the leading developing countries. He used DEA model for evaluating the performance of road safety systems in his study. The results showed that development of vehicle safety, the structure of road safety management, and postcrash response are most needed in Iran.

According to the WHO (2015) report, Iran with 32.1 fatalities rate per 100000 and $6 \%$ GDP lost due to road accidents in each year is among countries with poor performance in this field. Policy makers are trying to execute and monitor domestic road safety programs to improve safety of roads. In this study, the road safety performances in provinces of Iran are evaluated using DEA based road safety (DEARS) model in uncertain condition. In fact, it is assumed that there is uncertainty in inputs and outputs and it is necessary to develop DEA-RS model with uncertain data. This paper uses credibility fuzzy approach to develop DEA-RS in uncertain condition and constructs a novel credibility DEA-RS model. In fact, the constraint of DEA-RS model are considered as credibility constraints and a counterpart credibility DEA-RS (CreDEA-RS) model is proposed for evaluating road safety of provinces of Iran.

The rest of paper is as follows: in section 2 the proposed credibility DEA model used in this paper is described. In section 3, data of Iranian provinces road safety has been presented. The results are analyzed in section 4. Finally, conclusion of the paper is summarized in section 5.

\section{Methodology}

In this section, the proposed fuzzy DEA based road safety (DEA-RS) model is presented. The fuzzy DEA-RS model of this paper is developed based on the credibility approach. Credibility theory, introduced by Liu $(2002,2004)$ is a powerful method in fuzzy set theory. Unfortunately, credibility mathematical programming is complex and difficult to solve. In this paper, a novel credibility DEARS model is introduced which is easy to solve and analysis. 


\subsection{Preliminaries}

In this section, some basic definitions of fuzzy sets are reviewed. For more details, the readers can refer to Dubois and Prade (1978), Zimmermann (2001), Liu and Liu (2002, 2003) and Li and Liu (2006).

Definition 1: Let $U$ be a universe set. A fuzzy set $\tilde{A}$ of $U$ is defined by a membership function $\mu_{\tilde{A}}(x) \rightarrow[0,1], \forall \mathrm{x} \in \mathrm{U}$.

Definition 2: The $\alpha-$ cut of fuzzy set $\tilde{A}, \tilde{A}_{\alpha}$, is the crisp set $\tilde{A}_{\alpha}=\left\{x \mid \mu_{\tilde{A}}(x) \geq \alpha\right\}$.

Definition 3: A fuzzy number L-R type is expressed as $\tilde{A}=(m, \alpha, \beta)_{L R}$ with below membership function:

$$
\mu_{\tilde{A}}(x)= \begin{cases}L\left(\frac{m-x}{\alpha}\right) & x \leq m \\ R\left(\frac{x-m}{\beta}\right) & x \geq m\end{cases}
$$

where $L$ and $R$ are the left and right functions, respectively, and $\alpha$ and $\beta$ are the (non-negative) left and right spreads, respectively.

Definition 4: An L-R fuzzy number, $\tilde{A}=(\mathrm{m}, \alpha, \beta)_{L R}=(m, \alpha, \beta)$ is a triangular fuzzy number if

$$
L(x)=R(x)= \begin{cases}1-x & 0 \leq x \leq 1 \\ 0 & \text { otherwise }\end{cases}
$$

Definition 5: Let $\tilde{A}=(\mathrm{m}, \alpha, \beta)_{L R}$ and $\tilde{B}=(\overline{\mathrm{m}}, \bar{\alpha}, \bar{\beta})_{L R}$ be two positive triangular fuzzy numbers. The addition and subtraction of $\tilde{A}$ and $\tilde{B}$ are as follows:

Addition: $\tilde{A}+\tilde{B}=(m, \alpha, \beta)_{L R}+(\bar{m}, \bar{\alpha}, \bar{\beta})_{L R}=(m+\bar{m}, \alpha+\bar{\alpha}, \beta+\bar{\beta})_{L R}$

Subtraction: $\tilde{A}-\tilde{B}=(m, \alpha, \beta)_{L R}-(\bar{m}, \bar{\alpha}, \bar{\beta})_{L R}=(m-\bar{m}, \alpha+\bar{\beta}, \beta+\bar{\alpha})_{L R}$

Definition 6: A possibility space is defined as $(\Theta, P(\Theta), P o s)$ where $\Theta$ is nonempty set, $P(\Theta)$ is the power set of $\Theta$ and $P o s$ is the possibility measure. The possibility measure satisfies the below axioms:

1. $\operatorname{Pos}(\varnothing)=0, \operatorname{Pos}(X)=1$;

2. $\forall A, B \in P(\Theta)$, if $A \subseteq B \rightarrow \operatorname{Pos}(A) \leq \operatorname{Pos}(\mathrm{B})$;

3. $\operatorname{Pos}\left(A_{1} \cup A_{2} \ldots \cup A_{k}\right)=\operatorname{SupPos}_{j}\left(A_{j}\right)$

where $X$ is the universe set.

Definition 7: The necessity measure is defined as $\operatorname{Nec}(A)=1-\operatorname{Pos}\left(\mathrm{A}^{c}\right)$ where $A^{c}$ is the complementary set of $A$ set. The necessity measure satisfies the below axioms:

1. $\operatorname{Nec}(\varnothing)=0, \operatorname{Nec}(\mathrm{X})=1$;

2. $\forall A, B \in P(\Theta)$, if $A \subseteq B \rightarrow N e c(A) \leq N e c(\mathrm{~B})$;

3. $\operatorname{Pos}\left(A_{1} \cap A_{2} \ldots \cap A_{k}\right)=\operatorname{Inf} \operatorname{Nec}_{j}\left(A_{j}\right)$ 
Definition 8: The credibility measure is defined as $\operatorname{Cre}(A)=\frac{1}{2}\{\operatorname{Pos}(A)+\operatorname{Nec}(A)\}$. The credibility measure satisfies the below axioms:

1. $\operatorname{Cre}(\varnothing)=0, \operatorname{Cre}(\mathrm{X})=1$;

2. $\forall A, B \in P(\Theta)$, if $A \subseteq B \rightarrow \operatorname{Cre}(A) \leq \operatorname{Cre}(\mathrm{B})$;

3. $\operatorname{Cre}(A)+\operatorname{Cre}\left(A^{c}\right)=1, \forall A \subseteq P(X)$

Definition 9: Let $\lambda$ be a fuzzy variables. The possibility, necessity and credibility of the fuzzy event $(\lambda \geq r)$ are defined as:

$$
\begin{aligned}
& \operatorname{Pos}(\lambda \geq r)=\operatorname{Sup}_{t \geq r} \mu_{\lambda}(t) \\
& \operatorname{Nec}(\lambda \geq r)=1-\operatorname{Pos}(\lambda<r)=1-\operatorname{Sup} \underset{\lambda<r}{\mu_{\lambda}(t)} \\
& \operatorname{Cre}(\lambda \geq r)=\frac{1}{2}\{\operatorname{Pos}(\lambda \geq r)+\operatorname{Nec}(\lambda \geq r)\}
\end{aligned}
$$

\subsection{Data envelopment analysis-based road safety (DEA-RS)}

DEA is a nonparametric method that uses linear programming to measure the efficiency of DMUs with multiple inputs and multiple outputs. In DEA, efficiency is defined as a ratio of weighted sum of outputs to a weighted sum of inputs. Output-oriented DEA models maximize output for a given quantity of input factors, Contrariwise, input-oriented models minimize input factors required for a given level of output. The input oriented DEA-VRS model is as follows (Banker et al., 1984):

$$
\begin{aligned}
& \theta_{o}^{V R S}=\min \theta \\
& s t: \\
& \sum_{j=1}^{n} \lambda_{j} x_{i j} \leq \theta x_{i o}, i=1, \ldots, m \\
& \sum_{j=1}^{n} \lambda_{j} y_{r j} \geq y_{r o}, r=1, \ldots, \mathrm{s} \\
& \sum_{j=1}^{n} \lambda_{j}=1 \\
& \lambda_{j} \geq 0, j=1, \ldots, n \\
& \theta \text { free }
\end{aligned}
$$

In model (3), jth DMU uses $m$ inputs $x_{1 j}, \ldots, x_{m j}$ for producing $s$ outputs $y_{(m+1) j}, \ldots, x_{(m+s) j} . x_{i o}$ and $y_{r o}$ are the inputs and outputs of DMU under consideration, respectively. Also, the efficiency score of DMU under evaluation denotes as $\theta_{o}^{C C R}$. The model (3) is not appropriate for evaluating the road safety (Shen et al., 2012). As Shen et al. (2012) expressed, in DEA-based road safety model, we want the output, i.e., the number of road fatalities to be as low as possible with respect to the given input levels. In other words, in DEA-based road safety model proposed by Shen et al. (2012), efficient DMUs are those with minimum output levels in a given input levels. The DEA-based road safety (DEA-RS) model proposed by Shen et al. (2012) can be expressed as follows: 
$\theta_{o}^{D E A-R S}=\min \theta$

st :

$\sum_{j=1}^{n} \lambda_{j} x_{i j} \geq x_{i o}, i=1, \ldots, m$

$\sum_{j=1}^{n} \lambda_{j} y_{r j} \leq \theta y_{r o}, r=1, \ldots, \mathrm{s}$

$\sum_{j=1}^{n} \lambda_{j}=1$

$\lambda_{j} \geq 0, j=1, \ldots, n$

$\theta$ free

\subsection{Credibility DEA-RS (CreDEA-RS)}

In this section, the proposed credibility DEA-RS (CreDEA-RS) model is described. For developing DEA-RS using fuzzy credibility approach, first following lemma is proven.

Lemma: Let $\widetilde{\lambda}_{1}=\left(m_{1}, \alpha_{1}, \beta_{1}\right)_{L R}$ and $\widetilde{\lambda_{2}}=\left(m_{2}, \alpha_{2}, \beta_{2}\right)_{L R}$ be two L-R fuzzy numbers with continuous membership functions. For a given confidence level $\gamma \in[0,1]$ it is proven that:

I) If $\gamma \leq 0.5$, then $\operatorname{Cr}\left(\tilde{\lambda}_{1} \geq \tilde{\lambda}_{2}\right) \geq \gamma \Leftrightarrow m_{1}+\beta_{1} R^{-1}(2 \gamma) \geq m_{2}-\alpha_{2} R^{-1}(2 \gamma)$

II) If $\gamma>0.5$, then $\operatorname{Cr}\left(\tilde{\lambda}_{1} \geq \tilde{\lambda}_{2}\right) \geq \gamma \Leftrightarrow m_{1}-\alpha_{1} L^{-1}(2(1-\gamma)) \geq m_{2}+\beta_{2} L^{-1}(2(1-\gamma))$

Proof. Suppose that

$$
\tilde{\lambda}=\widetilde{\lambda}_{1}-\widetilde{\lambda}_{2}=\left(m_{1}, \alpha_{1}, \beta_{1}\right)_{L R} \oplus\left(-m_{2}, \beta_{2}, \alpha_{2}\right)_{L R}=\left(m_{1}-m_{2}, \alpha_{1}+\beta_{2}, \alpha_{2}+\beta_{1}\right)_{L R}=(\bar{m}, \bar{\alpha}, \bar{\beta})_{L R}
$$

According to definition 9 , we have:

$$
\begin{aligned}
& \operatorname{Cr}\left(\widetilde{\lambda}_{1} \geq \widetilde{\lambda}_{2}\right)=\operatorname{Cr}\left(\widetilde{\lambda}_{1}-\widetilde{\lambda}_{2} \geq 0\right)=\operatorname{Cr}(\tilde{\lambda} \geq 0)=\frac{1}{2}\left[P_{0},(\tilde{\lambda} \geq 0)+\operatorname{Nec}(\tilde{\lambda} \geq 0)\right] \\
& =\frac{1}{2}\left[P_{0},(\tilde{\lambda} \geq 0)+1-P_{0},(\tilde{\lambda} \geq 0)\right]=\frac{1}{2}\left[\sup _{t \geq 0} \mu(t)+1-\sup _{t<0} \mu(t)\right]
\end{aligned}
$$

It is clear that the Eq. (6) can be expressed as follows:

$$
\operatorname{Cr}(\tilde{\lambda} \geq 0)=\left\{\begin{array}{cc}
1 & 0 \leq \bar{m}-\bar{\alpha} \\
\frac{1}{2}\left[1+1-L\left(\frac{\bar{m}}{\bar{\alpha}}\right)\right]=1-\frac{1}{2} L\left(\frac{\bar{m}}{\bar{\alpha}}\right) & \bar{m}-\bar{\alpha} \leq 0 \leq \bar{m} \\
\frac{1}{2}\left[R\left(-\frac{\bar{m}}{\bar{\beta}}\right)+1-1\right]=\frac{1}{2} R\left(\frac{\bar{m}}{\bar{\beta}}\right) & \bar{m} \leq 0 \leq \bar{m}+\bar{\beta} \\
0 & \bar{m}+\bar{\beta}<0
\end{array}\right.
$$

If $\gamma \leq 0.5$, then 
$C_{r}(\tilde{\lambda} \geq 0) \geq \gamma \Leftrightarrow \frac{1}{2} R\left(\frac{-\bar{m}}{\bar{\beta}}\right) \geq \gamma \Leftrightarrow R\left(\frac{-\bar{m}}{\bar{\beta}}\right) \geq 2 \gamma \Leftrightarrow \frac{-\bar{m}}{\bar{\beta}} \leq R^{-1}(2 \gamma) \Leftrightarrow-\frac{m_{1}-m_{2}}{\alpha_{2}+\beta_{1}} \leq R^{-1}(2 \gamma)$

$\Leftrightarrow m_{1}-m_{2} \leq\left(\alpha_{2}+\beta_{1}\right) R^{-1}(2 \gamma) \Leftrightarrow m_{1}+\beta_{2} R^{-1}(2 \gamma) \geq m_{2}-\alpha_{2} R^{-1}(2 \gamma)$

If $\gamma>0.5$, then

$C_{r}(\tilde{\lambda} \geq 0) \geq \gamma \Leftrightarrow 1-\frac{1}{2} L\left(\frac{\bar{m}}{\bar{\alpha}}\right) \geq \gamma \Leftrightarrow \frac{1}{2} L\left(\frac{\bar{m}}{\bar{\alpha}}\right) \leq 1-\gamma \Leftrightarrow L\left(\frac{\bar{m}}{\bar{\alpha}}\right) \leq 2(1-\gamma)$

$\Leftrightarrow \frac{\bar{m}}{\bar{\alpha}} \geq L^{-1}(2(1-\gamma)) \Leftrightarrow \frac{m_{1}-m_{2}}{\alpha_{1}+\beta_{2}} \geq L^{-1}(2(1-\gamma)) \Leftrightarrow m_{1}-m_{2} \geq\left(\alpha_{1}+\beta_{2}\right) L^{-1}(2(1-\gamma))$

$\Leftrightarrow m_{1}-\alpha_{1} L^{-1}(2(1-\gamma)) \geq m_{2}+\beta_{2} L^{-1}(2(1-\gamma))$

The counterpart CreDEA-RS model can be expressed as follows:

$\theta_{o}^{C r e D E A-R S}=\min \theta$

st :

$\operatorname{Cr}\left(\sum_{j=1}^{n} \lambda_{j} x_{i j} \geq x_{i o}\right) \geq \gamma_{i}, i=1, \ldots, m$

$\operatorname{Cr}\left(\sum_{j=1}^{n} \lambda_{j} y_{r j} \leq \theta y_{r o}\right) \geq \gamma_{r}, r=1, \ldots, \mathrm{s}$

$\sum_{j=1}^{n} \lambda_{j}=1$

$\lambda_{j} \geq 0, j=1, \ldots, n$

$\theta$ free

In this study, the data are considered as triangular fuzzy numbers. Hence, according to definition 4, we have:

$$
L(x)=R(x)=L^{-1}(x)=R^{-1}(x)=1-x
$$

According to above lemma, for $\gamma_{i} \leq 0.5$, the first constraint of model (8) is expressed as follows:

$$
\begin{aligned}
& \sum \lambda_{j} x_{i j}{ }^{m}+\sum \lambda_{j} x_{i j}{ }^{\beta} R^{-1}\left(2 \gamma_{i}\right) \geq x_{i o}{ }^{m}-x_{i o}{ }^{\beta} R^{-1}\left(2 \gamma_{i}\right) \\
& \Rightarrow \sum \lambda_{j} x_{i j}{ }^{m}+\sum \lambda_{j} x_{x j}{ }^{\beta}\left(1-2 \gamma_{i}\right) \geq x_{i o}{ }^{m}-x_{i o}{ }^{\beta}\left(1-2 \gamma_{i}\right) \\
& \Rightarrow \sum_{j=1}^{n} \lambda_{j}\left[x_{i j}{ }^{m}+\left(1-2 \gamma_{i}\right) x_{i j}{ }^{\beta}\right] \geq x_{i o}{ }^{m}-\left(1-2 \gamma_{i}\right) x_{i o}{ }^{\beta}
\end{aligned}
$$

In addition, the second constraint of model (8) is converted to a linear constraint as follows:

$$
\begin{aligned}
& \theta y_{r o}{ }^{m}+\theta y_{r o}{ }^{\beta} R^{-1}\left(2 \gamma_{r}\right) \geq \sum \lambda_{j} y_{r j}{ }^{m}-\sum \lambda_{j} y_{r j}{ }^{\alpha} R^{-1}\left(2 \gamma_{r}\right) \\
& \Rightarrow \theta y_{r o}{ }^{m}+\theta y_{r o}{ }^{\beta}\left(1-2 \gamma_{r}\right) \geq \sum \lambda_{j} y_{r j}{ }^{m}-\sum \lambda_{j} y_{r j}{ }^{\alpha}\left(1-2 \gamma_{r}\right) \\
& \Rightarrow \sum_{j=1}^{n} \lambda_{j}\left[y_{r j}{ }^{m}-\left(1-2 \gamma_{r}\right) y_{i j}{ }^{\alpha}\right] \leq \theta\left[y_{r o}{ }^{m}+\left(1-2 \gamma_{r}\right) y_{r o}{ }^{\beta}\right]
\end{aligned}
$$


By considering the constraints (10) and (11), the final CreDEA-RS model for $\gamma_{i}, \gamma_{r} \leq 0.5$ is as follows: $\theta_{o, \gamma_{i}, \gamma_{r} \leq 0.5}^{C r e D E A S}=\min \theta$

st :

$\sum_{j=1}^{n} \lambda_{j}\left[x_{i j}{ }^{m}+\left(1-2 \gamma_{i}\right) x_{i j}{ }^{\beta}\right] \geq x_{i o}{ }^{m}-\left(1-2 \gamma_{i}\right) x_{i o}{ }^{\beta}, i=1, \ldots, m$

$\sum_{j=1}^{n} \lambda_{j}\left[y_{r j}{ }^{m}-\left(1-2 \gamma_{r}\right) y_{i j}{ }^{\alpha}\right] \leq \theta\left[y_{r o}{ }^{m}+\left(1-2 \gamma_{r}\right) y_{r o}{ }^{\beta}\right], r=1, \ldots, \mathrm{s}$

$\sum_{j=1}^{n} \lambda_{j}=1$

$\lambda_{j} \geq 0, j=1, \ldots, n$

$\theta$ free

In addition, according to above lemma, for $\gamma_{i}>0.5$, the first constraint of model (8) is expressed as follows:

$$
\begin{aligned}
& \sum \lambda_{j} x_{i j}{ }^{m}-\sum \lambda_{j} x_{i j}{ }^{\alpha} L^{-1}\left(2\left(1-\gamma_{i}\right)\right) \geq x_{i o}{ }^{m}+x_{i o}{ }^{\beta} R^{-1}\left(2\left(1-\gamma_{i}\right)\right) \\
& \Rightarrow \sum \lambda_{j} x_{i j}{ }^{m}-\sum \lambda_{j} x_{x j}{ }^{\beta}\left(2 \gamma_{i}-1\right) \geq x_{i o}{ }^{m}+x_{i o}{ }^{\beta}\left(2 \gamma_{i}-1\right) \\
& \Rightarrow \sum_{j=1}^{n} \lambda_{j}\left[x_{i j}{ }^{m}-\left(2 \gamma_{i}-1\right) x_{i j}{ }^{\beta}\right] \geq x_{i o}{ }^{m}+\left(2 \gamma_{i}-1\right) x_{i o}{ }^{\beta} .
\end{aligned}
$$

In addition, the second constraint of model (8) is converted to a linear constraint as follows:

$$
\begin{aligned}
& \theta y_{r o}{ }^{m}-\theta y_{r o}{ }^{\alpha} L^{-1}\left(2\left(1-\gamma_{r}\right)\right) \geq \sum \lambda_{j} y_{r j}{ }^{m}+\sum \lambda_{j} y_{r j}{ }^{\beta} L^{-1}\left(2\left(1-\gamma_{r}\right)\right) \\
& \Rightarrow \theta y_{r o}{ }^{m}-\theta y_{r o}{ }^{\alpha}\left(2 \gamma_{r}-1\right) \geq \sum \lambda_{j} y_{r j}{ }^{m}+\sum \lambda_{j} y_{r j}{ }^{\alpha}\left(2 \gamma_{r}-1\right) \\
& \Rightarrow \sum_{j=1}^{n} \lambda_{j}\left[y_{r j}{ }^{m}+\left(2 \gamma_{r}-1\right) y_{i j}{ }^{\alpha}\right] \leq \theta\left[y_{r o}{ }^{m}-\left(2 \gamma_{r}-1\right) y_{r o}{ }^{\alpha}\right] .
\end{aligned}
$$

Finally, the CreDEA-RS model for $\gamma_{i}, \gamma_{r}>0.5$ is as follows:

$$
\begin{aligned}
& \theta_{o, \gamma_{i}, \gamma_{r}>0.5}^{\operatorname{Cr} A-R S}=\min \theta \\
& s t: \\
& \sum_{j=1}^{n} \lambda_{j}\left[x_{i j}{ }^{m}-\left(2 \gamma_{i}-1\right) x_{i j}{ }^{\beta}\right] \geq x_{i o}{ }^{m}+\left(2 \gamma_{i}-1\right) x_{i o}{ }^{\beta}, i=1, \ldots, m \\
& \sum_{j=1}^{n} \lambda_{j}\left[y_{r j}{ }^{m}+\left(2 \gamma_{r}-1\right) y_{i j}{ }^{\alpha}\right] \leq \theta\left[y_{r o}{ }^{m}-\left(2 \gamma_{r}-1\right) y_{r o}{ }^{\alpha}\right], r=1, \ldots, \mathrm{s} \\
& \sum_{j=1}^{n} \lambda_{j}=1 \\
& \lambda_{j} \geq 0, j=1, \ldots, n \\
& \theta \text { free }
\end{aligned}
$$

\section{Data}

In this section, the proposed CreDEA-RS model is used for evaluating the road safety in 31 provinces of Iran. Iran is one of the worst performance countries in terms of road incidents. According to the WHO (2015) report, the average number of deaths per 100,000 people in the world is equal to 17.4 , 
while in Iran is 32.1 , which is approximately twice the global average. Also, road crashes lead to lose of about $6 \%$ of GDP in Iran annually, which is approximately twice the global average again. In this study, five inputs and three outputs are selected for estimating the efficiency scores of road safety in provinces in Iran. The inputs are passenger kilometer, tone kilometer, free/highway length $(\mathrm{km})$, number of registered automobile and number of speed camera. Also, three outputs of number of fatalities, number of injuries and number of crashes are chosen for analyzing. These variables are used to assess the road safety of the provinces. Provided data series involves annual data on 31 provinces observed in 2015. These data are retrieved from Iran Road Maintenance \& Transportation Organization (www.rmto.ir). The raw data are reported in Table 1, briefly.

\section{Table 1}

The brief raw data for provinces of Iran

\begin{tabular}{|c|c|c|c|c|c|c|c|c|}
\hline & \multicolumn{5}{|c|}{ Inputs } & \multicolumn{3}{|c|}{ Outputs } \\
\hline & $\begin{array}{l}\text { Passenger } \\
\text { kilometer }\end{array}$ & $\begin{array}{l}\text { Tone } \\
\text { kilometer }\end{array}$ & $\begin{array}{l}\text { Free/highway } \\
\text { length }(\mathrm{km})\end{array}$ & $\begin{array}{l}\text { Number of } \\
\text { registered } \\
\text { automobile }\end{array}$ & $\begin{array}{l}\text { Number of } \\
\text { speed } \\
\text { camera }\end{array}$ & $\begin{array}{l}\text { Number of } \\
\text { fatalities }\end{array}$ & $\begin{array}{l}\text { Number of } \\
\text { injuries }\end{array}$ & $\begin{array}{l}\text { Number of } \\
\text { crashes }\end{array}$ \\
\hline Min & 680.00 & 1905.00 & 87.00 & 7946.00 & 0.00 & 110.00 & 3123.00 & 1169.00 \\
\hline Max & 13197.00 & 45057.00 & 2094.00 & 448419.00 & 136.00 & 1076.00 & 41384.00 & 12364.00 \\
\hline Mean & 3026.74 & 13400.74 & 613.81 & 48927.00 & 31.68 & 359.00 & 10744.06 & 4457.16 \\
\hline St. Dev & 2848.71 & 12021.11 & 497.67 & 80366.93 & 32.19 & 219.28 & 8764.60 & 2881.50 \\
\hline
\end{tabular}

\section{Results}

In this section, the provinces of Iran are evaluated based on the proposed CreDEA-RS model. Without losing any generality, we assume that $\gamma=\gamma_{i}=\gamma_{r}$. For sensitivity analysis, the proposed model is implemented for $\gamma=0.4,0.5,0.6,0.8,1$. For $\gamma=0.4,0.5$ the model (12) and for $\gamma=0.6,0.8,1$, the model (15) has been used. Table 2 reports the efficiencies for $\gamma=0.4,0.5$. By setting the value of $\gamma=0.5$, the result are shown in Table 2. Based on the results obtained for the $\gamma=0.5$, the CreDEA-RS model is converted to the DEA-RS model and the results are consistent with the DEA-RS model. As can be seen in Table 2, 13 provinces have better performance than other provinces and they have the efficiency score equal to 1. In contrary, Gilan, West Azarbaijan and East Azarbaijan provinces with the scores of $0.3921,0.4332$ and 0.4405 respectively have the worst performance. In fact, with selecting $\gamma=0.5$, the proposed CreDEA-RS model does not consider any uncertainty in data and it is converted to the DEARS model (4). With setting the value of $\gamma$ to 0.4 , the efficiency scores are re-calculated. According to the results reported in Table 2, four provinces of Ilam, Charmal and Bakhtiari, South Khorasan and Hormoongan with the efficiency score of 0.9607 have been better than other provinces in terms of road safety. As shown in Table 2, the efficiency scores have been reduced compared to the $\gamma=0.5$, but the ranking has not changed.

Table 2

The results of CreDEA-RS model for $\gamma \leq 0.5$

\begin{tabular}{|c|c|c|c|c|c|}
\hline Provinces & $\gamma=0.5$ & $\gamma=0.4$ & Provinces & $\gamma=0.5$ & $\gamma=0.4$ \\
\hline East Azarbaijan & 0.4332 & 0.4051 & Fars & 1 & 0.9168 \\
\hline West Azarbaijan & 0.4405 & 0.4124 & Qazvin & 0.7949 & 0.7475 \\
\hline Ardabil & 0.9261 & 0.8811 & Qom & 0.9558 & 0.8848 \\
\hline Esfahan & 1 & 0.9375 & Kurdistan & 0.5905 & 0.5674 \\
\hline Alborz & 0.6744 & 0.6447 & Kerman & 1 & 0.9343 \\
\hline Ilam & 1 & 0.9607 & Kermanshah & 0.4534 & 0.4268 \\
\hline Bushehr & 1 & 0.9432 & $\begin{array}{l}\text { Kohgiluye\& } \\
\text { Boyerahmad }\end{array}$ & 0.7966 & 0.7624 \\
\hline Tehran & 1 & 0.9358 & Golestan & 0.5914 & 0.5598 \\
\hline $\begin{array}{l}\text { Chaharmahal \& } \\
\text { Bakhtiari }\end{array}$ & 1 & 0.9607 & Gilan & 0.3921 & 0.3682 \\
\hline South-Khorasan & 1 & 0.9607 & Lorestan & 0.5013 & 0.4733 \\
\hline Razavi Khorasan & 1 & 0.9239 & Mazandaran & 0.4813 & 0.4436 \\
\hline North Khorasan & 0.851 & 0.8101 & Markazi & 0.599 & 0.5542 \\
\hline Khuzestan & 1 & 0.9009 & Hormozgan & 1 & 0.9607 \\
\hline Zanjan & 0.7024 & 0.667 & Hamedan & 0.739 & 0.6848 \\
\hline Semnan & 1 & 0.9436 & Yazd & 1 & 0.9588 \\
\hline Sistan \& Baluchestan & 0.8039 & 0.748 & & & \\
\hline
\end{tabular}


For $\gamma=1$, the provinces of Hormozgan and Guilan have the best and worst performance among the 31 provinces, respectively. The Kurdistan and Yazd provinces have the second and third positions, respectively. The results of the proposed CreDEA-RS model are shown in Table 3. The worst road safety situation in this ranking belongs to Guilan province with a score of 0.5412 . The provinces of West Azarbaijan and East Azarbaijan with the scores of 0.6161 and 0.6248 respectively have the second and third worst road safety conditions, respectively. In addition, the advantage of the proposed CreDEA-RS model is the complete ranking in comparison to the DEA-RS model. The model is applied for values $\gamma=0.8$ and $\gamma=0.6$ and the results are presented in Table 3 . According to the results of the proposed model, decreasing the value of $\gamma$ decreases the efficiency values, but the rating does not change, significantly. For instance, for $\gamma=0.6$, Gilan province has the worst score. However, the statuses of West Azarbaijan and East Azarbaijan provinces have changed in ranking, and East Azarbaijan Province has been ranked 30th. At the top of the Table 3, there is no significant change in ranking.

\section{Table 3}

The results of CreDEA-RS model for $\gamma>0.5$

\begin{tabular}{|c|c|c|c|c|c|c|c|}
\hline Provinces & $\gamma=1$ & $\gamma=0.8$ & $\gamma=0.6$ & Provinces & $\gamma=1$ & $\gamma=0.8$ & $\gamma=0.6$ \\
\hline East Azarbaijan & 0.6248 & 0.5321 & 0.4639 & Fars & 1.2711 & 1.1536 & 1.0481 \\
\hline West Azarbaijan & 0.6161 & 0.5379 & 0.4706 & Qazvin & 1.1438 & 0.9797 & 0.848 \\
\hline Ardabil & 1.1942 & 1.0773 & 0.9736 & Qom & 1.4098 & 1.2058 & 1.0326 \\
\hline Esfahan & 1.2796 & 1.037 & 1.0497 & Kurdistan & 0.7262 & 0.6665 & 0.6146 \\
\hline Alborz & 0.8604 & 0.7793 & 0.707 & Kerman & 3.2382 & 2.4941 & 1.444 \\
\hline Ilam & 1.452 & 1.2497 & 1.0768 & Kermanshah & 0.6178 & 0.545 & 0.4819 \\
\hline Bushehr & 1.8057 & 1.4369 & 1.132 & Kohgiluye\& Boyerahmad & 0.9997 & 0.9101 & 0.8325 \\
\hline Tehran & 2.0286 & 1.1276 & 1.0362 & Golestan & 0.7828 & 0.6987 & 0.625 \\
\hline Chaharmahal \& Bakhtiari & 1.3574 & 1.1993 & 1.0619 & Gilan & 0.5412 & 0.475 & 0.4178 \\
\hline South-Khorasan & 2.1222 & 1.6046 & 1.1815 & Lorestan & 0.7785 & 0.6121 & 0.5326 \\
\hline Razavi Khorasan & 1.06 & 1.1338 & 1.0631 & Mazandaran & 0.7274 & 0.6149 & 0.522 \\
\hline North Khorasan & 1.094 & 0.9882 & 0.8941 & Markazi & 0.977 & 0.7931 & 0.6543 \\
\hline Khuzestan & 1.6211 & 1.4701 & 1.2103 & Hormozgan & 4.4214 & 2.8232 & 1.5412 \\
\hline Zanjan & 0.9188 & 0.8223 & 0.74 & Hamedan & 1.0916 & 0.9332 & 0.7986 \\
\hline Semnan & 2.4269 & 1.7662 & 1.2292 & Yazd & 2.429 & 1.7677 & 1.2297 \\
\hline Sistan \& Baluchestan & 1.1824 & 1.0057 & 0.8643 & & & & \\
\hline
\end{tabular}

\section{Conclusion}

In this study, the road safety performances in provinces of Iran were evaluated using DEA based road safety (DEA-RS) model under uncertain conditions. This paper has used credibility fuzzy approach to develop DEA-RS under uncertain condition and constructed a novel credibility DEA-RS model. In fact, the constraints of DEA-RS model were considered as credibility constraints and a counterpart credibility DEA-RS (CreDEA-RS) model was proposed for evaluating road safety of provinces of Iran. According to the results, provinces located in mountainous and forest areas such as Gilan had a much weaker performance than provinces in desert areas such as Yazd. The results of the proposed model have indicated that decreasing the value of $\gamma$ decreases the efficiency values, but the rating did not change significantly.

\section{References}

Aron, M., Seidowsky, R., \& Cohen, S. (2013). Safety impact of using the hard shoulder during congested traffic. The case of a managed lane operation on a French urban motorway. Transportation Research Part C: Emerging Technologies, 28, 168-180.

Banker, R. D., Charnes, A., \& Cooper, W. W. (1984). Some models for estimating technical and scale inefficiencies in data envelopment analysis. Management Science, 30(9), 1078-1092.

Bao, Q., Ruan, D., Shen, Y., Hermans, E., \& Janssens, D. (2012). Improved hierarchical fuzzy TOPSIS for road safety performance evaluation. Knowledge-based systems, 32, 84-90. 
Behnood, H.R. (2018). Best practice analysis of action for road safety in Iran amongst the leading developing countries using an optimized success indicator. Transport Policy, 66, 76-84.

Chen, F., Wu, J., Chen, X., Wang, J., \& Wang, D. (2016). Benchmarking road safety performance: Identifying a meaningful reference (best-in-class). Accident Analysis \& Prevention, 86, 76-89.

Dubois, D., \& Prade, H. (1978) Operations on fuzzy numbers. International Journal of Systems Sciences 9(6), 613-626

Gitelman, V., Doveh, E., \& Hakkert, S. (2010). Designing a composite indicator for road safety. Safety Science, 48(9), 1212-1224.

Hermans, E., Brijs, T., Wets, G., \& Vanhoof, K. (2009). Benchmarking road safety: lessons to learn from a data envelopment analysis. Accident Analysis \& Prevention, 41(1), 174-182.

Li, X., \& Liu, B. (2006). A sufficient and necessary condition for credibility measures. International Journal of Uncertainty. Fuzziness and Knowledge-Based Systems, 14(5), 527-535.

Liu, B. (2002). Toward fuzzy optimization without mathematical ambiguity. Fuzzy Optimization and Decision Making, 1(1), 43-63.

Liu, B. (2004). Uncertainty theory: An introduction to its axiomatic foundations. Berlin: SpringerVerlag.

Liu, B., \& Liu, Y. K. (2002). Expected value of fuzzy variable and fuzzy expected value models. IEEE Transactions on Fuzzy Systems, 10(4), 445-450.

Liu, Y. K., \& Liu, B. (2003). Fuzzy random variables: A scalar expected value operator. Fuzzy Optimization and Decision Making, 2(2), 143-160.

Nikolaou, P., \& Dimitriou, L. (2018). Evaluation of road safety policies performance across Europe: Results from benchmark analysis for a decade. Transportation Research Part A: Policy and Practice, 116, 232-246.

Rosic, M., Resic, D., Kukic, D., Antic, B., \& Bozovic, M. (2018). Method for selection of optimal road safety composite index with examples from DEA and TOPSIS method. Accident Analysis \& Prevention, 98, 277-286.

Shen, Y., Hermans, E., Bao, Q., Brijs, T., \& Wets, G. (2015). Serious injuries: an additional indicator to fatalities for road safety benchmarking. Traffic Injury Prevention, 16(3), 246-253.

Shen, Y., Hermans, E., Brijs, T., Wets, G., \& Vanhoof, K. (2012). Road safety risk evaluation and target setting using data envelopment analysis and its extensions. Accident Analysis \& Prevention, 48, 430-441.

Wang, J., \& Huang, H. (2016). Road network safety evaluation using Bayesian hierarchical joint model. Accident Analysis \& Prevention, 90, 152-158.

Wegman, F., \& Oppe, S. (2010). Benchmarking road safety performances of countries. Safety Science, 48(9), 1203-1211.

Yannis, G., Weijermars, W., Gitelman, V., Vis, M., Chaziris, A., Papadimitriou, E., \& Azevedo, C. L. (2013). Road safety performance indicators for the interurban road network. Accident Analysis \& Prevention, 60, 384-395.

Zimmermann, H. J. (2001). Fuzzy sets theory and its applications (fourth ed.). Dordrecht, The Netherlands: Kluwer Academic Publishers.

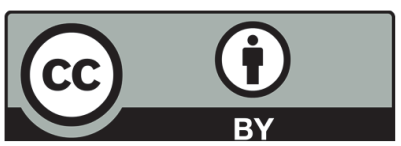

(C) 2019 by the authors; licensee Growing Science, Canada. This is an open access article distributed under the terms and conditions of the Creative Commons Attribution (CC-BY)

license (http://creativecommons.org/licenses/by/4.0/). 